\title{
Micropuncture Study of Inorganic Phosphate Excretion in the Rat*
}

\author{
James C. Strickler, $†$ David D. Thompson, Ruth M. Klose, and \\ Gerhard Giebisch $\ddagger$ WiTh the technical assistanCe of \\ Judith N. Gluck and Judith B. Vaughan \\ (From the Departments of Medicine and Physiology, Cornell University Mcdical College, \\ Ncw York, N.Y.)
}

The mechanism by which the mammalian kidney excretes inorganic phosphate has not been fully elucidated. The only micropuncture data available are those of Walker and Hudson (1), and they deal with the mode of phosphate excretion in two amphibian species. These investigators reported that the inorganic phosphate concentration rises progressively along the proximal and distal nephron of the frog and Necturus. In the frog this rise can be accounted for by tubular fluid reabsorption, but in the Necturus the secretion of phosphate could not always be excluded. Evidence obtained by clearance experiments in vertebrates indicates significant species differences. Thus, renal tubular phosphate secretion has been conclusively demonstrated in certain fish (2-4), the alligator (5), and the chicken (6). The mechanism of phosphate excretion in the mammalian kidney, on the other hand, has remained, to some extent, controversial. According to Pitts and Alexander, in the dog (7) there is a maximal tubular reabsorptive capacity for phosphate, the renal transfer of phosphate being achieved by a combination of glomerular filtration and subse-

* Submitted for publication December 26, 1963; accepted April 21, 1964.

Supported by grants from the Life Insurance Medical Research Fund, the National Science Foundation, and the American Heart Association.

A short report appeared in abstract form (Fed. Proc. 1963, 22, 631).

† Part of this work was done as a Special Research Fellow of the National Heart Institute, U. S. Public Health Service. Career Scientist of the Health Research Council of the City of New York.

$\ddagger$ Part of this work was done during the tenure of an Established Investigatorship of the American Heart Association. Supported by a U. S. Public Health Research Career Program Award (5-K6-AM-18) from the National Institute of Arthritis and Metabolic Diseases. quent tubular reabsorption. Similarly, phosphate reabsorption by the human kidney seems ratelimited (8). Attempts to demonstrate a similar tubular transfer maximum in the cat (9) and vitamin D-treated aparathyroid rat (10) have been less successful, since tubular reabsorption of phosphate in these instances appears to increase in direct proportion to the filtered load. Ginn, however, has found saturation kinetics for renal tubular phosphate reabsorption in normal and magnesium-deficient rats (11).

Stop-flow studies in the dog by Pitts, Gurd, Kessler, and Hierholzer (12) and by Malvin, Wilde, and Sullivan (13) have furnished evidence which demonstrates that the main site of phosphate reabsorption is the proximal tubule, a notion also supported by other indirect observations. These include inhibition of phosphate reabsorption by glucose (7), sodium hippurate (14), and bicarbonate (15), substances believed to be transferred at the same site within the nephron. Also pertinent is the observation that subsequent to the administration of an inorganic phosphate tracer, radioactivity is maximal within the proximal convoluted tubule, the presumed site of a metabolically driven reabsorptive process (16).

Several investigators have proposed that inorganic phosphate may also be secreted into the mammalian tubule (17-20). Thus, Nicholson and Shepherd have interpreted their data in favor of distal tubular secretion of this ion species in the dog, since they were able to suppress urinary phosphate excretion subsequent to selective toxic damage of the distal tubule (17). Furthermore, Carrasquer and Brodsky (18), measuring urinary phosphate and creatinine in phosphate-loaded dogs after intra-arterial injections, observed changes which they interpreted as greater excretion of 
phosphate than creatinine. This enhancement of phosphate excretion appeared to be $\mathrm{pH}$-dependent (21). However, Handler (22) was unable to demonstrate phosphate secretion under conditions of stable elevated plasma phosphate levels, despite a number of manipulations that enhance urinary loss of this ion, including parathyroid administration and phosphate loading. Thus, unequivocal evidence for net phosphate secretion in mammals is not available.

The present study was undertaken to investigate the problem of phosphate excretion in a mammalian species more directly by micropuncture techniques. Samples of proximal and distal tubular fluid from rats with endogenous phosphate levels were analyzed for inorganic phosphate and radioinulin and compared with samples collected from phosphate-loaded animals. The concentration of inorganic phosphate at various nephron sites as well as the fraction of filtered phosphate remaining within the tubular lumen could thus be estimated as a function of the nephron site. Our data indicate that the proximal tubular epithelium is the main site of inorganic phosphate reabsorption. At high plasma levels this reabsorptive mechanism becomes saturated. No evidence for renal tubular phosphate secretion was obtained.

\section{Methods}

Experiments were performed on white, male albino rats anesthetized by intraperitoneal injection of sodium pentobarbital, 30 to $40 \mathrm{mg}$ per $\mathrm{kg}$. Normal and phosphate-loaded animals, weighing 300 to $450 \mathrm{~g}$, were studied. The technique of preparing the animals for micropuncture, tubular fluid sampling, and localization of the puncture site have previously been described in a paper from this laboratory (23). Purina lab chow (calcium $1.42 \%$, phosphate, $0.96 \%$ ) was available to both groups of animals until 15 to 18 hours before an experiment. Free access to water was permitted. All animals received an intravenous priming dose of $50 \mu \mathrm{c}$ of $\mathrm{C}^{14}$ carboxyl inulin ${ }^{1}$ dissolved in $0.6 \mathrm{ml}$ of $0.85 \%$ saline. During the subsequent 3 to 5 hours about $50 \mu \mathrm{c}$ of $\mathrm{C}^{14}$ inulin was infused per hour. For the control animals, this was dissolved in $0.85 \%$ saline and delivered at a rate of $3.0 \mathrm{ml}$ per hour. Ureteral urine from the experimental kidney was collected into either acid-rinsed Wintrobe hematocrit tubes, or small graduated cylinders. Tail blood, taken before and after collection of tubular fluid, was drawn into heparinized glass tubing. Tubular fluids, obtained by micropuncture, were transferred to

${ }^{1}$ New England Nuclear Corp., Boston, Mass. 0.5-mm acid-rinsed glass tubing, juxtaposed by mineral oil. The ends of the tubing were sealed with plasticin.

The phosphate-loaded rats were injected intraperitoneally with 3 mmoles per $\mathrm{kg}$ of sodium phosphate $(\mathrm{pH}$ 7.0 to 7.2) daily for 3 to 4 days before an experiment. During this time their drinking water contained $1.5 \%$ ammonium chloride. During experiments these animals were infused with 150 mmoles $\mathrm{NaH}_{2} \mathrm{PO}_{4}$ at a rate of 0.0146 mmole per minute. This regimen was adopted to achieve high rates of urinary phosphate excretion (18, 21).

Tubular fluids and the supernatant fluids of plasma and urine after addition of trichloroacetic acid (TCA) were analyzed for inorganic phosphate and $\mathrm{C}^{14}$ inulin. In the smaller tubular fluid samples only phosphate was determined. To minimize contamination with phosphate, all glassware was acid-soaked after washing with Lakeseal detergent.

Plasma for phosphate determination was prepared in $0.8-\mathrm{mm}$ Pyrex glass tubing placed over a $1-\mathrm{cm} 100-\mathrm{U}$ micrometer disc on a microscope stage. One end of the tubing was attached to a microsyringe, an arrangement similar to the original water-manipulator used by Westfal, Findley, and Richards (24). Under a dissecting microscope, plasma was pipetted into the open end of the tubing and sufficient $90 \%$ TCA added to achieve a final TCA concentration of $8 \%$. The ends of the tube were closed by flaming in a small oxygen-gas flame, and mixing was accomplished by centrifuging, inverting, and recentrifuging a total of 6 times. The supernatant fluid was withdrawn and used for phosphate analysis and assays of radioactivity. After appropriate dilutions with $8 \%$ TCA, samples of urine were centrifuged, and the supernatant fluid was retained for analysis.

We adapted the inorganic phosphate method described by Chen, Toribara, and Warner (25) for ultramicroanalytical determinations of tubular fluid and TCA-filtrates of plasma and urine. The basis of this reaction is the color formed by ascorbic acid reduction of a phosphomolybdate complex. A composite reagent (reagent C), freshly prepared for each series of determinations, and kept at $4^{\circ} \mathrm{C}$ until used, consisted of 1 part $2.5 \mathrm{~N}$ sulfuric acid, 1 part $2.5 \%$ ammonium-molybdate, ${ }^{2}$ and 1 part $10 \%$ ascorbic acid. ${ }^{3}$ For optimal color development this reagent must be prepared in the order mentioned and mixed thoroughly after each addition. With $0.2 \mu \mathrm{l}$ of 8\% TCA used for the blank, a phosphate standard curve was prepared from triplicate analyses of 3 standards $\left(0.2 \mu \mathrm{l}\right.$ of $0.5,2.0$, and 4.0 mmoles per $\mathrm{L}$ as $\left.\mathrm{KH}_{2} \mathrm{PO}_{4}\right)$ for each set of unknowns. A standard curve was plotted with each experiment and a straight-line relationship between the log of percentage of transmission and the concentration of phosphate was observed. Seven replications of a $4.0 \mathrm{mM}$ phosphate solution (vol, $0.2 \mu \mathrm{l}$ ) were measured with a standard deviation of $\pm 3 \%$. The recovery of inorganic phosphate added to plasma averaged $96 \%$.

2 J. T. Baker Chemical Co., Phillipsburg, N. J.

${ }^{3}$ Mallinckrodt Chemical Works, St. Louis, Mo. 
TABLE I

Ratios of concentration of phosphate in ultrafiltrate to that in plasma and plasma water in control animals*

\begin{tabular}{|c|c|c|c|c|c|c|c|}
\hline \multirow[b]{2}{*}{ Rat } & \multicolumn{2}{|c|}{$\mathrm{pH}$} & \multirow[b]{2}{*}{ Protein } & \multicolumn{4}{|c|}{ Inorganic phosphate } \\
\hline & $\overline{W B}$ & $\mathrm{VF}$ & & Plasma & UF & $\mathrm{UF} / \mathrm{P}$ & $\mathrm{UF} / \mathrm{P}_{\mathrm{H}_{2} \mathrm{O}}$ \\
\hline & & & $\mathrm{g} / 100 \mathrm{ml}$ & mmoles $/ L$ & mmoles $/ L$ & & \\
\hline 1 & & 7.46 & 6.28 & 2.20 & 2.05 & 0.93 & 0.88 \\
\hline 2 & & 7.39 & 6.69 & 2.04 & 2.07 & 1.01 & 0.95 \\
\hline 3 & & 7.36 & 6.16 & 2.11 & 1.89 & 0.89 & 0.84 \\
\hline 4 & & 7.45 & 6.31 & 2.56 & 2.35 & 0.92 & 0.86 \\
\hline 5 & & 7.33 & 5.69 & 2.02 & 1.86 & 0.92 & 0.87 \\
\hline 6 & & 7.43 & 6.57 & 1.64 & 1.47 & 0.89 & 0.84 \\
\hline 7 & & 7.35 & 7.10 & 2.60 & 2.57 & 0.99 & 0.92 \\
\hline 8 & & 7.38 & 6.15 & 1.92 & 1.75 & 0.91 & 0.86 \\
\hline 9 & & 7.40 & 6.25 & 3.68 & 3.41 & 0.93 & 0.87 \\
\hline 10 & & 7.36 & 6.74 & 2.06 & 1.92 & 0.93 & 0.88 \\
\hline 11 & & 7.39 & 6.81 & 1.06 & 1.08 & 1.02 & 0.95 \\
\hline 12 & & 7.39 & 6.77 & 1.10 & 1.11 & 1.01 & 0.95 \\
\hline 13 & & 7.34 & 7.10 & 2.35 & 2.38 & 1.01 & 0.94 \\
\hline 14 & & & 6.56 & 2.37 & 2.48 & 1.05 & 0.98 \\
\hline 15 & & 7.37 & 7.15 & 2.10 & 2.06 & 0.98 & 0.92 \\
\hline $\begin{array}{l}\text { Mean } \\
\text { SD }\end{array}$ & & & 6.56 & 2.12 & 2.03 & $\begin{array}{r}0.96 \\
+0.050\end{array}$ & $\begin{array}{r}0.90 \\
+0.045\end{array}$ \\
\hline
\end{tabular}
water.

${ }^{*} \mathrm{WB}=$ whole blood, $\mathrm{UF}=$ ultrafiltrate, $\mathrm{P}=$ plasma concentration of inorganic phosphate, and $\mathrm{P}_{\mathrm{H}_{2} \mathrm{O}}=$ plasma

Phosphate analyses were performed in $0.5-\mathrm{mm}$ constant bore Pyrex glass tubing, with the same watermanipulator system as previously described for the preparation of plasma filtrates. Initially, $20 \mathrm{U}$ (approximately $0.2 \mu 1$ ) of unknown or standard was introduced into the tubing and withdrawn for a distance of $1 \mathrm{~cm}$. After interposition of an air space, a column of reagent $C$, measuring $60 \mathrm{U}$, was added. In those instances in which the tubular fluid sample was smaller than $20 \mathrm{U}(0.2 \mu \mathrm{l})$, the remainder of the initial $20-\mathrm{U}$ volume was made up with $8 \%$ TCA. After drawing unknown and reagent further into the tubing, the ends were flame-sealed and the contents mixed by centrifugation. Color was developed in a water bath at $37^{\circ} \mathrm{C}$ for 90 minutes. The intensity of the color so formed remained stable for at least 6 hours. Optical density of the unknowns and standards, contained in their original glass tubing, was measured in a Zeiss spectrophotometer (820 $\mathrm{m} \mu$; slit width, $0.3 \mathrm{~mm}$ ).

A microcuvette holder specially constructed to fit into the cell holders ( $\mathrm{S}$-cells) of a Zeiss spectrophotometer (PMQ 11) was used. This holder consists of two identical brass pieces, measuring $8 \times 6 \times 37 \mathrm{~mm}$ each and held together by machine screws. A semicircular groove machined longitudinally down the opposing surfaces of each piece forms, when juxtaposed, a hollow central core that snugly accommodates $0.5-\mathrm{mm}$ o.d. tubing. The hub of a number 20 -gauge hypodermic needle, positioned into the upper end of the core, facilitates introduction and withdrawal of the glass tubing into the holder. A through mid-line slit, in the lower third of the assembled holder, permits light transmission. The longitudinal dimension of this slit may be altered by inserting a matching piece of a number 20 -gauge needle into the bottom end of the hollow core. To correct for variations in light transmission due to different positions of the glass tube within the cuvette each glass tubing was randomly rotated within the sample holder, and the results of ten readings were averaged. The error due to such variation is included in the previously mentioned standard deviation.

To approximate inorganic phosphate concentration in the glomerular filtrate, the filterability of phosphate in rat plasma has been measured by the ultrafiltration method described by Toribara, Terepka, and Dewey (26). Normal and phosphate-loaded rats were anesthetized with sodium pentobarbital, and blood samples were obtained by aortic puncture. In six of these latter experiments, the blood was withdrawn anaerobically into heparinized, oiled syringes for $\mathrm{pH}$ measurements, made within 5 minutes of a sampling at $37^{\circ} \mathrm{C}$ with a Radiometer $\mathrm{pH}$ meter. The method of Chen, Toribara, and Warner (25) was employed without modification for inorganic phosphate determinations of plasma TCA filtrates and the ultrafiltrates. For $\mathrm{pH}$ measurements the ultrafiltrate was collected anaerobically by puncturing the plastic (Tygon) tubing that connects the side-arms of the Toribara ultrafiltration chamber. Plasma protein concentrations were determined by the biuret method (27) and read in a Zeiss spectrophotometer at $520 \mathrm{~m} \mu$. These protein concentrations were used to calculate phosphate concentrations in plasma water.

$\mathrm{C}^{14}$ carboxyl inulin was estimated in a Tri-Carb liquid scintillation spectrometer ${ }^{4}$ as previously described (23). The concentration of inulin was corrected to that of plasma water by assuming a protein content of $7 \mathrm{~g}$ per $100 \mathrm{ml}$.

\footnotetext{
4 Packard Instrument Co., I aGrange, Ill., model 314X.
} 
TABLE II

Ratios of concentration of phosphate in ultrafiltrate to that in plasma and plasma water in phosphate-loaded animals

\begin{tabular}{|c|c|c|c|c|c|c|c|}
\hline \multirow[b]{2}{*}{ Rat } & \multicolumn{2}{|c|}{$\mathrm{pH}$} & \multirow[b]{2}{*}{ Protein } & \multicolumn{4}{|c|}{ Inorganic phosphate } \\
\hline & WB & UF & & Plasma & UF & $\mathrm{UF} / \mathrm{P}$ & $\mathrm{UF} / \mathrm{P}_{\mathbf{2}} \mathrm{O}$ \\
\hline $\begin{array}{l}1 \\
2 \\
3 \\
5 \\
6 \\
7 \\
8 \\
9\end{array}$ & $\begin{array}{l}7.25 \\
7.35 \\
\\
7.14 \\
7.28 \\
7.38\end{array}$ & $\begin{array}{l}7.26 \\
7.34 \\
\\
7.36 \\
7.33 \\
7.42\end{array}$ & $\begin{array}{c}\mathrm{g} / 100 \mathrm{ml} \\
4.94 \\
5.96 \\
5.65 \\
\mathbf{5 . 7 3} \\
5.48 \\
\mathbf{5 . 4 8} \\
4.85 \\
\mathbf{5 . 3 8}\end{array}$ & $\begin{array}{c}\text { mmoles } / L \\
14.40 \\
7.40 \\
8.20 \\
6.26 \\
7.74 \\
8.10 \\
11.09 \\
13.89\end{array}$ & $\begin{array}{c}\text { mmoles } / L \\
14.36 \\
7.20 \\
7.90 \\
5.83 \\
7.56 \\
7.81 \\
8.89 \\
3.85\end{array}$ & $\begin{array}{l}1.00 \\
0.97 \\
0.96 \\
0.93 \\
0.98 \\
0.96 \\
0.99\end{array}$ & $\begin{array}{l}0.95 \\
0.92 \\
0.91 \\
0.88 \\
0.92 \\
0.91 \\
\\
0.94\end{array}$ \\
\hline $\begin{array}{l}\text { Mean } \\
\text { SD }\end{array}$ & & & 5.34 & & & 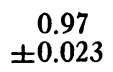 & $\begin{array}{c}0.92 \\
\pm 0.023\end{array}$ \\
\hline
\end{tabular}

\section{Results}

Tables I and II summarize data obtained from the ultrafiltration experiments. Table I shows the results on control rat plasma; Table II shows the results on plasma from animals that were phosphate-loaded. The $\mathrm{pH}$ of ultrafiltrate of control plasma varied between 7.34 and 7.46. The mean total protein concentration for this group was 6.56 g per $100 \mathrm{ml}$, the mean plasma inorganic phosphate, 2.12 mmoles per $\mathrm{L}$, and the mean phosphate content of the ultrafiltrate, 2.03 mmoles per $\mathrm{L}$. The ratio of the phosphate concentration in ultrafiltrate to that in plasma (UF/P) averaged 0.96 $\pm 0.05(\mathrm{SD})$; the ratio of phosphate concentra-

TABLE III

Inorganic phosphate and inulin concentrations of proximal tubular fuid, plasma, and urine from rats with endogenous phosphate levels*

\begin{tabular}{|c|c|c|c|c|c|c|}
\hline \multirow[b]{2}{*}{ Rat } & \multirow[b]{2}{*}{ Localization } & \multicolumn{2}{|c|}{ Inulin } & \multicolumn{3}{|c|}{ Inorganic phosphate } \\
\hline & & $\mathrm{TF} / \mathrm{P}$ & $\overline{\mathrm{U} / \mathrm{P}}$ & Plasma & $\mathrm{TF} / \mathrm{P}$ & $\mathrm{U} / \mathrm{P}$ \\
\hline \multirow{26}{*}{$\begin{array}{r}1 \\
1 \\
1 \\
1 \\
2 \\
2 \\
2 \\
3 \\
3 \\
3 \\
4 \\
4 \\
4 \\
4 \\
5 \\
7 \\
7 \\
8 \\
9 \\
10 \\
11 \\
12 \\
13 \\
13\end{array}$} & $\% P$ & & & mmoles $/ L$ & & \\
\hline & 50 & & 279 & 2.50 & 0.80 & 118 \\
\hline & 45 & 1.66 & 243 & 2.29 & 0.81 & 118 \\
\hline & 25 & 1.16 & 153 & 1.78 & 0.67 & 103 \\
\hline & 40 & 1.67 & 158 & 2.02 & 0.75 & 107 \\
\hline & 50 & & 507 & 2.95 & 0.56 & 80.5 \\
\hline & 45 & 3.70 & 412 & 2.86 & 0.48 & 70.6 \\
\hline & 50 & & 282 & 2.81 & 0.60 & 75.2 \\
\hline & 50 & 2.94 & 340 & 2.62 & 0.78 & 81.1 \\
\hline & 30 & 1.38 & 375 & 2.78 & 1.10 & 98.1 \\
\hline & 45 & 2.13 & 266 & 2.46 & 0.74 & 73.6 \\
\hline & 30 & & 284 & 4.08 & 0.75 & 27.6 \\
\hline & 65 & & 247 & 3.72 & 0.55 & 46.5 \\
\hline & 45 & 2.85 & 312 & 3.39 & 0.89 & 65.1 \\
\hline & 50 & & 323 & 3.16 & 0.88 & 49.5 \\
\hline & 20 & & 838 & 3.20 & 0.63 & 23.8 \\
\hline & 40 & & & 2.90 & 0.79 & \\
\hline & 65 & & & 3.13 & 0.59 & $r$ \\
\hline & 40 & 1.56 & 401 & 3.39 & 0.91 & 66.0 \\
\hline & 55 & & 209 & 3.81 & 0.53 & / 14.1 \\
\hline & 20 & & 406 & 2.27 & 0.95 & 48.1 \\
\hline & 45 & & 875 & 4.98 & 0.51 & 14.9 \\
\hline & 60 & & 630 & 2.68 & 0.70 & 166 \\
\hline & 35 & & 412 & 3.03 & 0.59 & 66.7 \\
\hline & 50 & 3.91 & 528 & 2.71 & 0.97 & 106 \\
\hline & & & & Mean $=$ & $\begin{array}{l}0.73 \\
\pm 0.16(\mathrm{SD})\end{array}$ & \\
\hline
\end{tabular}

* TF = tubular fluid, $\mathrm{U}=$ urine, and $\% \mathrm{P}=$ percentage of proximal tubule; other abbreviations as in Table $\mathrm{I}$, 


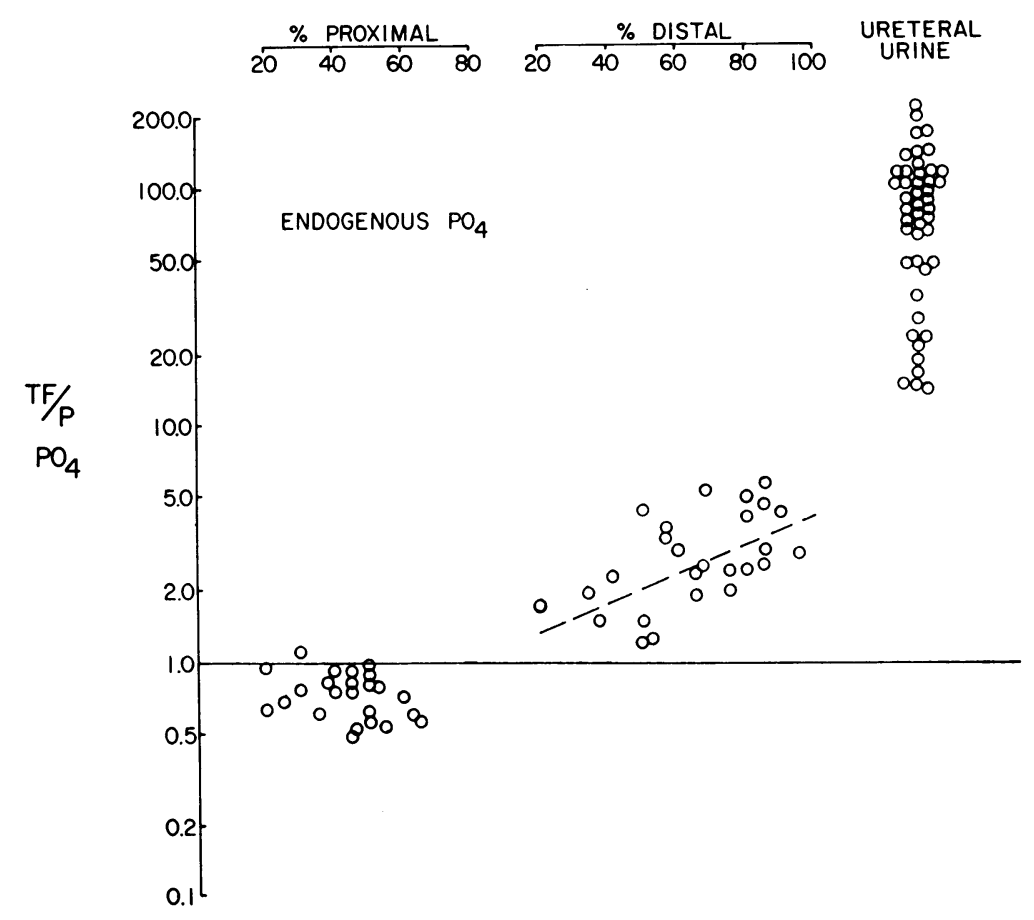

Fig. 1. Summary of phosphate concentration ratios [tubular fluid (TF)/PLASMa (P)] AS a FUnCtion OF tUbULAR LeNGTh in CONTROL RATS.

tion in ultrafiltrate to that in plasma water (UF/ $\mathrm{P}_{\mathbf{H}_{2} \mathrm{O}}$ ) averaged $0.90 \pm 0.045(\mathrm{SD})$. In the micropuncture experiments, plasma phosphate values were multiplied by the figure 0.96 , to approximate the phosphate concentration in the glomerular filtrate.

The $\mathrm{pH}$ of ultrafiltrate of plasma from phosphate-loaded animals was generally lower than from the control animals and corresponded closely to the $\mathrm{pH}$ of aortic blood at the time of collection. Mean total protein concentration, $5.43 \mathrm{~g}$ per 100 $\mathrm{ml}$, was somewhat lower in the phosphate-infused rats than in the controls, presumably due to expansion of intravascular volume. Phosphate infusion elevated the plasma phosphate to values between 6.26 and 14.4 mmoles per L. The UF/P ratio averaged $0.97 \pm 0.023(\mathrm{SD})$, the $U F / \mathrm{P}_{\mathrm{H}_{2} \mathrm{O}}$ ratio, $0.92 \pm 0.023$ (SD). In the micropuncture experiments in phosphate-luaded animals, plasma phosphate values were multiplied by 0.97 , to approximate the phosphate concentration in glomerular filtrate.

Tables III and IV summarize the data obtained from micropuncture experiments performed on control animals. The average plasma phosphate concentration for the control rats was 2.92 mmoles per $\mathrm{L} \pm 0.09(\mathrm{SD})$ and is slightly lower than values recently reported by Kenny (28). Twentyfour samples were collected from sites ranging from 20 to $65 \%$ of the proximal convolution. Inulin tubular fluid to plasma $(\mathrm{TF} / \mathrm{P})$ ratios, determined for 10 of these samples, varied between 1.16 and 3.91, indicating the extent of water reabsorption along this portion of the nephron. Extensive over-all water absorption for this group of animals is indicated by a mean inulin urine to plasma $(U / P)$ ratio of 390 . With but one exception the phosphate $\mathrm{TF} / \mathrm{P}$ ratios in the proximal tubule are below unity with a mean of $0.73 \pm 0.16$ (SD), indicating that phosphate is being reabsorbed in greater proportion than water. Figure 1 shows these phosphate ratios plotted as a function of tubular length. The $\mathrm{U} / \mathrm{P}$ phosphate ratio varied considerably and averaged 89 .

From the distal convolution, 26 samples were obtained from sites between 20 and $90 \%$ of tubular length (Table IV). Inulin ratios, estimated in 11 of these samples, ranged from 3.74 in the early distal to 16.0 in the late distal tubule. These proximal and distal $\mathrm{TF} / \mathrm{P}$ inulin ratios are in general 
TABLE IV

Inorganic phosphate and inulin concentrations of distal tubular fluid, plasma, and urine from rats with endogenous phosphate levels*

\begin{tabular}{|c|c|c|c|c|c|c|}
\hline \multirow[b]{2}{*}{ Rat } & \multirow[b]{2}{*}{ Localization } & \multicolumn{2}{|c|}{ Inulin } & \multicolumn{3}{|c|}{ Inorganic phosphate } \\
\hline & & $\mathrm{TF} / \mathrm{P}$ & $\mathrm{U} / \mathrm{P}$ & Plasma & $\mathrm{TF} / \mathrm{P}$ & $\mathrm{U} / \mathrm{P}$ \\
\hline \multicolumn{7}{|c|}{ moles $/ L$} \\
\hline 6 & 50 & \multirow[t]{2}{*}{14.0} & \multirow{6}{*}{$\begin{array}{l}246 \\
177 \\
604 \\
594 \\
625\end{array}$} & 2.27 & 1.20 & 19.1 \\
\hline 9 & 85 & & & 3.96 & 2.92 & 24.7 \\
\hline 12 & 85 & \multirow{4}{*}{$\begin{array}{l}9.02 \\
7.57\end{array}$} & & 2.89 & 2.55 & 86.9 \\
\hline 12 & 75 & & & 2.83 & 1.99 & 115 \\
\hline 13 & 50 & & & 2.77 & 1.22 & 101 \\
\hline 13 & 50 & & & 2.79 & 1.49 & 107 \\
\hline 14 & 80 & \multirow{4}{*}{$\begin{array}{l}10.8 \\
16.0\end{array}$} & 393 & 3.14 & 2.43 & 90.2 \\
\hline 14 & 65 & & 519 & 2.81 & 2.35 & 113 \\
\hline 17 & 85 & & 358 & 3.20 & 5.60 & 117 \\
\hline 17 & 90 & & 403 & 3.04 & 4.29 & 139 \\
\hline 17 & 80 & 11.0 & 399 & 3.96 & 4.08 & 142 \\
\hline 20 & 20 & 3.74 & 327 & 2.37 & 1.88 & 82 \\
\hline 20 & 81 & 13.7 & 332 & 2.28 & 4.65 & 82 \\
\hline 19 & 95 & & 563 & 2.24 & 2.86 & 167 \\
\hline 19 & 65 & & 472 & 2.05 & 2.50 & 172 \\
\hline 19 & 75 & & 562 & 2.05 & 2.40 & 198 \\
\hline 19 & 65 & & 439 & 1.97 & 1.90 & 220 \\
\hline 21 & 37 & & & 2.83 & 1.49 & 35 \\
\hline 21 & 68 & 14.7 & 115 & 2.45 & 5.31 & 48 \\
\hline 28 & 65 & & 319 & 2.75 & 2.88 & 80.6 \\
\hline 28 & 56 & & 301 & 2.86 & 3.64 & 129 \\
\hline 28 & 85 & & & 2.78 & 4.62 & 103 \\
\hline 28 & 50 & & & 2.78 & 4.34 & 134 \\
\hline 29 & 41 & 11.7 & 279 & 3.76 & 2.26 & 15.1 \\
\hline 29 & 34 & 9.76 & 392 & 3.98 & 1.93 & 23.6 \\
\hline 29 & 60 & & & 3.88 & 1.96 & \\
\hline
\end{tabular}

$* \% \mathrm{D}=$ percentage of distal tubule.

agreement with values obtained under similar experimental conditions from this and other laboratories $(29,30)$. Column 5 of Table IV shows that the distal tubular $\mathrm{TF} / \mathrm{P}$ phosphate ratios are all above unity, ranging from 1.20 to a maximum of 5.60. As illustrated in Figure 1, phosphate concentration tends to rise progressively in this portion of the nephron. A straight line through these points, plotted by the method of least squares, shows a mean $\mathrm{TF} / \mathrm{P}$ ratio of 1.5 in the early distal $(30 \%)$ and slightly more than a twofold rise to a ratio of 3.6 in the late distal convolution (90\%). A comparison of TF/P phosphate with the respective inulin ratios (obtained in this and other studies) indicates that the rise in phosphate concentration along the distal tubule does not exceed that of inulin. Therefore, water reabsorption along this nephron segment can adequately account for the observed increase in phosphate concentration. A similar comparison shows that the average rise in inulin concentration between the distal tubule and ureteral urine slightly exceeds that of phosphate. The final urine/distal tubular fluid ratio for inulin averaged 41.4 compared to 30.6 for phosphate. We may conclude, therefore, that further fluid reabsorption along the collecting duct can account for the observed high phosphate concentrations in the final urine. From these considerations it appears that urinary phosphate excretion in the control rats is derived solely from the processes of glomerular filtration and tubular reabsorption.

Tables V and VI contain data from experiments on animals that were phosphate loaded. Plasma phosphate concentrations were elevated to levels between 7.60 and 17.48 mmoles per L. After 60 minutes of the phosphate infusion, the plasma phosphate levels often continued to rise gradually. If a greater than twofold increase occurred after the first hour of infusion, the experiment was discarded. Fourteen samples were collected from sites between 20 and $60 \%$ of proximal tubular length. Seven proximal inulin $\mathrm{TF} / \mathrm{P}$ ratios ranged between 1.22 and 2.39. Water reabsorption in the loaded animals was less than in the controls, as reflected by the lower mean inulin 
TABI.E V

Inorganic phosphate and inulin concentrations of proximal tubular fluid, plasma, and urine from phosphate-loaded rats

\begin{tabular}{|c|c|c|c|c|c|c|}
\hline \multirow[b]{2}{*}{ Rat } & \multirow[b]{2}{*}{ Localization } & \multicolumn{2}{|c|}{ Inulin } & \multicolumn{3}{|c|}{ Inorganic phosphate } \\
\hline & & $\mathrm{TF} / \mathrm{P}$ & $\mathrm{U} / \mathrm{P}$ & Plasma & $\mathrm{TF} / \mathrm{P}$ & $\mathrm{U} / \mathrm{P}$ \\
\hline & $\% P$ & \multicolumn{5}{|c|}{ mmoles $/ L$} \\
\hline 22 & 50 & & 50.3 & 7.94 & 1.31 & 50.4 \\
\hline 25 & 50 & 2.19 & 40.7 & 10.8 & 1.51 & 25.7 \\
\hline 25 & 42 & 1.90 & 36.9 & 11.2 & 1.42 & 27.3 \\
\hline 25 & 45 & 1.90 & 31.6 & 14.3 & 1.79 & 19.8 \\
\hline 25 & 47 & & 22.7 & 16.0 & 1.93 & 16.8 \\
\hline 26 & 30 & & 61.6 & 9.3 & 1.44 & 40.1 \\
\hline 27 & 54 & & 44.3 & 8.6 & 1.31 & 50.3 \\
\hline 27 & 60 & & 35.8 & 8.9 & 1.74 & 49.8 \\
\hline 27 & 20 & & & 9.7 & 1.13 & 43.4 \\
\hline 27 & 56 & & 54.7 & 7.9 & 1.90 & 53.4 \\
\hline 31 & 21 & 1.14 & 97.8 & 7.6 & 1.39 & 58.4 \\
\hline 31 & 39 & 1.83 & 81.3 & 9.9 & 1.13 & 47.7 \\
\hline 32 & 65 & 2.39 & 25.6 & 12.6 & 2.24 & 24.0 \\
\hline 33 & 47 & 1.22 & 80.7 & 7.7 & 1.32 & 56.7 \\
\hline
\end{tabular}

$\mathrm{U} / \mathrm{P}$ ratio of 49 (control, 390). In contrast to the results obtained in the control group, all proximal phosphate $T F / P$ ratios are above one, ranging from 1.13 to 2.24 . These ratios are plotted as a function of tubular length in Figure 2. With but one exception (no. 33) comparison of these phosphate ratios with the inulin ratios again shows that the rise in phosphate concentration does not exceed that which can be anticipated by water abstraction. The mean $\mathrm{U} / \mathrm{P}$ phosphate ratio for the loáded animals was 37 .

In one animal (no. 27) the final urine phosphate $U / P$ ratio exceeded that of inulin in two of three samples. This result suggests net phosphate secretion. Since this was the only animal in which this observation was made, however, and there was no obvious difference in the experimental approach, the result remains unexplained.
Nine samples were collected from sites between 22 and $80 \%$ of the distal convolution (Table VI). Inulin $\mathrm{TF} / \mathrm{P}$ ratios for eight of these samples ranged from 4.69 in the early distal to a maximal value of 13.2. The distal $\mathrm{TF} / \mathrm{P}$ phosphate ratios are all above unity with a low of 2.43 in the early distal and rising thereafter to a maximal value of 5.54. These ratios, shown in Figure 2, tend to increase progressively along this segment of the nephron. The straight line through these points, plotted by the method of the least squares, shows a mean ratio of 3.1 in the early distal $(20 \%)$ and less than a twofold rise to 4.9 in the late distal tubule $(90 \%)$. Comparison of respective $\mathrm{TF} / \mathrm{P}$ phosphate with inulin ratios again indicates that the rise in phosphate concentration along the distal tubule may be accounted for by water reabsorption. The greater mean rise of inulin $\mathrm{TF} / \mathrm{P}$

TABLE VI

Inorganic phosphate and inulin concentrations of distal tubular fluid, plasma, and urine from phosphate-loaded rats

\begin{tabular}{|c|c|c|c|c|c|c|}
\hline \multirow[b]{2}{*}{ Rat } & \multirow[b]{2}{*}{ Localization } & \multicolumn{2}{|c|}{ Inulin } & \multicolumn{3}{|c|}{ Inorganic phosphate } \\
\hline & & $\mathrm{TF} / \mathrm{P}$ & $\overline{U / P}$ & Plasma & TF $/ P$ & $\mathrm{U} / \mathrm{P}$ \\
\hline & $\% D$ & \multicolumn{5}{|c|}{ mmoles /I. } \\
\hline 31 & 75 & & 91.0 & 7.67 & 3.96 & 56.7 \\
\hline 31 & 55 & 4.66 & 82.2 & 8.45 & 4.21 & 48.9 \\
\hline 32 & 68 & 6.34 & 30.4 & 14.50 & 4.21 & 19.8 \\
\hline 32 & 22 & 3.71 & 23.8 & 17.48 & 2.43 & 15.9 \\
\hline 33 & 42 & 9.36 & 59.2 & 8.78 & 5.10 & 37.1 \\
\hline 33 & 73 & 4.51 & 47.2 & 9.64 & 4.38 & 37.2 \\
\hline 33 & 81 & 5.06 & 51.5 & 9.90 & 4.52 & 37.0 \\
\hline 34 & 56 & 13.2 & 45.5 & 12.90 & 5.54 & 17.7 \\
\hline 34 & 17 & 4.69 & 23.2 & 17.30 & 2.99 & 14.2 \\
\hline
\end{tabular}




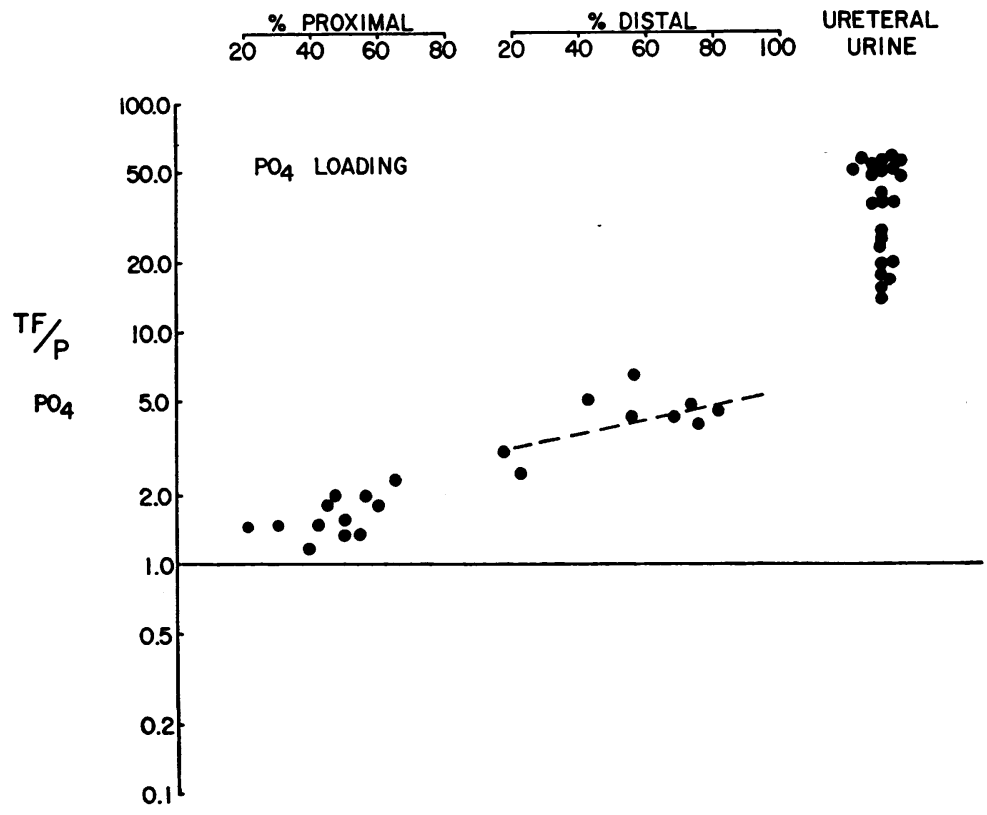

Fig. 2. Summary of phosphate concentration ratios (TF/P) as a FINCTION OF TUBLLAR LENGTH IN PHOSPHATE-LOADED RATS.

ratios (8-fold) than phosphate TF/P ratios (6.9fold) between distal tubule and final urine suggests that the final urinary phosphate concentration is achieved solely by fluid reabsorption along the collecting duct. These observations in the phosphate-loaded rats indicate that urinary phosphate concentration, as in controls, also results from the processes of glomerular filtration and tubular reabsorption.

\section{Discussion}

In a recent study of protein binding of phosphate in normal and uremic human plasma, Walser (31) emphasized that the ultrafiltration method of Toribara and associates (26) seems to yield a valid sample of fluid in equilibrium with plasma. He reported that the ratio of inorganic phosphate concentration in ultrafiltrate to that in plasma water of normal humans averages 0.825 and calculated that $76 \%$ of the plasma inorganic phosphate is freely filterable. Approximateiy the same fraction of phosphate in plasma from uremic patients, with and without elevated plasma phosphate levels, was found to be filterable (31).

Our studies of plasma from normal rats show that the ratio of phosphate concentration in the ultrafiltrate to that in plasma water averages 0.90 (Table I). If all plasma inorganic phosphate were ultrafilterable and if we assume a Donnan factor of 0.915 for the phosphate ions (32), then this ratio should be $1: 0.915$ or 1.09 . The filterable inorganic phosphate in normal rat plasma therefore comprises $0.90: 1.09$, or $82.5 \%$ of the total. A similar calculation for rat plasma with elevated phosphate levels indicates that $84.5 \%$ (0.92:1.09) is ultrafilterable. These studies on plasma obtained from both normal and phosphateloaded rats indicate that slightly more than threefourths of the inorganic phosphate is filterable through cellophane.

Benjamin and Hess (33) reported a mean ratio of phosphate concentration in ultrafiltrate to that of plasma from immature rats averages 0.93 . These investigators, however, corrected the observed phosphate concentration of the ultrafiltrate for volume reduction due to nonfilterability of plasma proteins. If this correction factor is eliminated, their mean ratio becomes 0.965 . The corresponding ratios obtained in this study were 0.96 for the control rats and 0.97 for the phosphateloaded animals.

Our data from micropuncture experiments in both phosphate-loaded rats and in animals with endogenous phosphate levels indicate that phosphate excretion by the rat kidney can be accounted for by glomerular filtration and tubular reabsorp- 
tion. In both groups most of this reabsorptive process takes place in the proximal convolution. A quantitative estimate of the fraction of filtered phosphate reabsorbed proximally may be obtained from an evaluation of the reduction in the volume of the glomerular filtrate and the transtubular filtrate and the transtubular phosphate concentration gradient. With an average end-proximal inulin $T F / P$ ratio of $3(29,30)$ and an average $T F / P$ phosphate of 0.73 in the control animals as a basis, we can calculate that $76 \%$ of the filtered phosphate is reabsorbed by the end of the proximal convolution. As previously noted, these calculations have been corrected for that portion of rat plasma phosphate which is nonfilterable. Carone has found $\mathrm{TF} / \mathrm{P}$ phosphate concentration ratios in the proximal and distal tubule of the rat which are similar to those presented in this study (34).

The relatively small intraluminal/peritubular phosphate concentration ratio $(0.73)$ is similar in magnitude to the corresponding ratios for sodium during mannitol infusions, and for potassium and calcium (35-37). A comparison of inulin with phosphate $T F / P$ ratios between the end of the proximal convolution and the final urine suggests that, in general, little additional reabsorption of this ion takes place either in the distal tubule or in the collecting duct. Further supporting this fact is the observation that the percentage of filtered phosphate remaining at the end of the proximal convolution [ $100 \%$ (amount filtered) $-76 \%$ $($ reabsorbed $)=24 \%$ ] approximates the mean fraction of filtered phosphate excreted $(22.5 \%)$.

As regards the proposed tubular mechanism of phosphate transport as studied by the micropuncture technique, two considerations deserve emphasis. First, since no data have been obtained on samples collected from the loop of Henle, we cannot exclude the possibility of continued phosphate reabsorption along this part of the nephron with subsequent secretory re-entry prior to the distal tubule. We regard the possibility of anion secretion across such a limited tubule segment as unlikely. Secondly, tubular samples were obtained from cortical nephrons only, whereas final urine is an admixture of fluid derived from nephrons having both short and long loops of Henle. Fluid emerging from the subcortical nephrons with longer loops might, because of greater water reabsorption, contain a higher concentration of inulin or phosphate, or both, than fluid emerging from shorter tubules with shorter loops and less concentrating ability. This consideration somewhat limits the significance of conclusions based on a comparison of phosphate and inulin concentrations between distal tubular fluid and the final urine.

The thesis that phosphate reabsorption in the rat kidney takes place largely in the proximal convolution is in accord with stop-flow studies $(12,13)$. It is further supported by the demonstrated inhibition of phosphate reabsorption by substances known to be reabsorbed or secreted proximally $(7,14,15)$ and the localization of isotope within the kidney after the administration of $\mathrm{P}^{32}$ as the orthophosphate (16).

A number of points indicate that proximal tubular phosphate reabsorption is an active process. Pertinent to this consideration are the relationships among transtubular phosphate movement, the intracellular concentration of this ion(s), and the electrical profile across the proximal tubular epithelium. A transtubular potential of $-20 \mathrm{mv}$ previously demonstrated in rats under the same experimental conditions as our control animals (38) can account for an even steeper concentration gradient than has been observed. ${ }^{5}$ However, this analysis of over-all ion movement (tubular lumen to peritubular fluid) ignores the individual electrochemical potential gradients that exist at the luminal and the peritubular cell membrane.

5 This statement is based upon application of the Nernst equation, $\mathrm{E}_{\mathrm{T}}=-61.5 \log$ [anion] $\mathrm{P} /[$ anion] $\mathrm{TF}$, where $\mathrm{E}_{\mathrm{T}}=$ transtubular potential difference, and [anion] $\mathrm{P}$ and [anion]TF $=$ the plasma and tubular fluid anion activity, respectively. By substituting a value of $-20 \mathrm{mv}$ for $E_{\mathrm{T}}$, a concentration ratio of 0.47 obtains for $T F / P$ phosphate. This relationship holds for passive distribution of a univalent anion at electrochemical equilibrium. The limiting $\mathrm{TF} / \mathrm{P}$ value for divalent anion distribution $\left[\mathrm{H}_{2} \mathrm{PO}_{4}{ }^{2}\right]$ would be even lower. It is obvious that under the present experimental conditions of net phosphate transfer, electrochemical equilibrium has not been attained. Thus, the observed mean phosphate $\mathrm{TF} / \mathrm{P}$ ratio of 0.73 , lying above the limiting concentration ratio, could indicate nonachievement of equilibrium. Although consistent with a passive distribution of phosphate across a membrane maintaining the above given electrical potential difference, this is not in itself proof against carrier-mediated transport. 
The exact concentration of phosphate in cell water of the proximal tubular cell of the rat is uncertain but is probably about 4.0 mmoles per $\mathrm{L}$ and significantly exceeds the concentration in plasma. ${ }^{6}$ This concentration gradient between tubular lumen and intracellular space would not favor transport of this ion out of the tubule. In addition, another energy barrier opposing net phosphate movement into the cell is present, since it is virtually certain that the interior of the proximal tubule cell is electrically more negative than the tubular lumen. It thus appears safe to conclude that the movement of anions across the luminal cell border occurs against an electrochemical potential gradient and thus qualifies as an active transport process. Similar considerations regarding transport of phosphate out of the cell across the peritubular cell membrane indicate movement down an electrochemical gradient. Such downhill ion movement is compatible with passive diffusion but does not exclude carriermediated transfer of phosphate at this site. Further supporting evidence for an active component of phosphate reabsorption may be found in studies demonstrating saturation kinetics of tubular reabsorption of phosphate and the competition with glucose, sodium hippurate, and $\mathrm{HCO}_{3}{ }^{-}$(7, $14,15)$.

Our experimental results during phosphate loading have not revealed evidence of tubular secretion of phosphate at any nephron site despite a markedly increased phosphate excretion rate as compared to the control group. A consideration of the segmental contribution to the over-all process of phosphate reabsorption in the loaded animals as compared to the controls indicates that the major difference resides in the proximal tubule. Concentration ratios of phosphate consistently above unity in the proximal segment indicate a limitation of the transfer capacity of this nephron

\footnotetext{
6 This estimate of intracellular inorganic phosphate was calculated on the basis of the following assumptions : 1) a total inorganic phosphate concentration in rat kidney cortex of no less than 3 mmoles per $\mathrm{kg}$ wet weight $(39), 2)$ an extracellular fluid volume of $0.24 \mathrm{ml}$ per $\mathrm{g}$ $(40), 3)$ a dry weight of rat kidney comprising $23 \%$ of total wet weight (41), and 4) an interstitial inorganic phosphate concentration closely approximating that in an ultrafiltrate of plasma.
}

segment for phosphate as the phosphate load is enhanced. We can estimate that in this group, assuming an end proximal inulin concentration ratio of 2.39 and a corresponding phosphate ratio of 1.80 , only some $22 \%$ of phosphate filtered is reabsorbed by the end of the proximal convolution. A similar estimate of phosphate reabsorption in animals with endogenous phosphate levels indicates that the absolute amount of phosphate ion proximally reabsorbed is comparable. ${ }^{7}$ This indicates that the reabsorptive capacity of this tubular segment is limited, and does not increase during phosphate loading.

\section{Summary}

Micropuncture studies performed on normal and phosphate-loaded rats indicate that the renal excretion of inorganic phosphate can be accounted for by processes of glomerular filtration and tubular reabsorption. No evidence for net tubular secretion of phosphate was obtained. In both groups of animals tubular reabsorption of phosphate takes place largely in the proximal convolution. The reabsorptive capacity of the proximal convolution for inorganic phosphate seems to be rate-limited and probably involves an active transport process.

7 The glomerular filtration rate (GFR) averaged 4.8 $\mathrm{ml}$ per minute per $\mathrm{kg}$ for both control and phosphateloaded rats. The amount of phosphate reabsorbed by the first two-thirds of proximal convolution of control rats can be estimated as follows : 1) Phosphate filtered $=$ mean plasma phosphate concentration $\times$ per cent filtered $\times \mathrm{GFR}=2.92$ mmoles per $\mathrm{L} \times 0.96 \times 0.0048 \mathrm{~L}$ per minute per $\mathrm{kg}=0.0135$ mmole per minute per $\mathrm{kg}$; 2) assuming a TF/P inulin ratio of 3.0 in the late proximal convolution, phosphate reaching this nephron segment $=\mathrm{GFR} /$ $3 \times$ mean plasma phosphate concentration $\times T F / P$ phosphate $=0.0048 \mathrm{~L}$ per minute per $\mathrm{kg} / 3 \times 2.92$ mmoles per $\mathrm{L} \times 0.73=0.0034$ mmole per $\mathrm{kg}$ per minute; 3) inorganic phosphate reabsorbed by the first two-thirds of the proximal convolution must equal 0.0135 mmole per minute per $\mathrm{kg}-0.0034$ mmole per minute per $\mathrm{kg}=0.0101$ mmole per minute per $\mathrm{kg}$.

A similar calculation for the phosphate-loaded animals, employing a mean plasma phosphate concentration of 10.87 mmoles per $\mathrm{L}$, a late proximal inulin $\mathrm{TF} / \mathrm{P}$ ratio of 2.4, and a late proximal phosphate $\mathrm{TF} / \mathrm{P}$ ratio of 1.80 (average of all ratios beyond $50 \%$ proximal), indicates that 0.0114 mmole per minute per $\mathrm{kg}$ of phosphate is reabsorbed by the first two-thirds of the proximal convolution. 


\section{References}

1. Walker, A. M., and C. L. Hudson. The role of the tubule in the excretion of inorganic phosphates by the amphibian kidney. Amer. J. Physiol. 1937, $118,167$.

2. Smith, W. W. The excretion of phosphate in the dog fish, Squalus acanthias. J. cell. comp. Physiol. 1939, 14, 95.

3. Marshall, E. K., Jr., and A. L. Grafflin. Excretion of inorganic phosphate by the aglomerular kidney. Proc. Soc. exp. Biol. (N. Y.) 1933, 31, 44.

4. Grafflin, A. L. Renal function in marine teleosts. Biol. Bull. 1936, 71, 360.

5. Hernandez, T., and R. A. Coulson. Renal clearance in the alligator. Fed. Proc. 1956, 15, 91.

6. Levinsky, N. G., and D. G. Davidson. Renal action of parathyroid extract in the chicken. Amer. J. Physiol. 1957, 191, 530.

7. Pitts, R. F., and R. S. Alexander. The renal reabsorptive mechanism for inorganic phosphate in normal and acidotic dogs. Amer. J. Physiol. 1944, $142,648$.

8. Thompson, D. D., and H. H. Hiatt. Renal reabsorption of phosphate in normal human subjects and in patients with parathyroid disease. J. clin. Invest. 1957, 36, 550.

9. Eggleton, M. G., and S. Shuster. Glucose and phosphate excretion in the cat. J. Physiol. (Lond.) 1954, 124, 613.

10. Crawford, J. D., D. Gribetz, and N. B. Talbot. Mechanism of renal tubular phosphate reabsorption and the influence thereon of vitamin $D$ in completely parathyroidectomized rats. Amer. J. Physiol. 1955, 180, 156.

11. Ginn, H. E. Personal communication.

12. Pitts, R. F., R. S. Gurd, R. H. Kessler, and K. Hierholzer. Localization of acidification of urine, potassium and ammonia secretion and phosphate reabsorption in the nephron of the dog. Amer. J. Physiol. 1958, 194, 125.

13. Malvin, R. L., W. S. Wilde, and L. P. Sullivan. Localization of nephron transport by stop flow analysis. Amer. J. Physiol. 1958, 194, 135.

14. Hendrix, B. M., and J. P. Saunders. The effect of injections of sodium phosphates and sodium hippurate upon the excretion of acid and ammonia by the kidney. J. biol. Chem. 1923, 58, 503.

15. Malvin, R., and W. Lotspeich. Relation between tubular transport of inorganic phosphate and bicarbonate in the dog. Amer. J. Physiol. 1956, 187, 51.

16. Taugner, R., H. V. Egidy, J. Iravani, and G. Taugner. Die Verteilung von radioaktivem Orthophosphate in der Katzenniere, untersucht mit Hilfe der Gefrierschnitt-Autoradiographie. Naunyn-Schmiedeberg's Arch. exp. Path. Pharmak. 1960, 238, 419.
17. Nicholson, T. F., and G. W. Shepherd. The effect of damage to various parts of the renal tubule on the excretion of phosphate by the dog's kidney. Canad. J. Biochem. 1959, 37, 103.

18. Carrasquer, G., and W. A. Brodsky. Transient secretion of phosphate in relation to underlying plasma level in the dog kidney. Amer. J. Physiol. 1960, 199, 1239.

19. Barclay, J. A., W. T. Cooke, and R. A. Kenney. The renal excretion of inorganic phosphate in man and dog. Acta med. scand. 1949, 134, 107.

20. Kleeman, C. R., and R. E. Cooke. The acute effects of parathyroid hormone on the metabolism of endogenous phosphate. J. Lab. clin. Med. 1951, 38, 112.

21. Carrasquer, G., and W. A. Brodsky. Elimination of transient secretion of phosphate by alkalinization of plasma in dogs. Amer. J. Physiol. 1961, 201, 499.

22. Handler, J. S. A study of renal phosphate excretion in the dog. Amer. J. Physiol. 1962, 202, 787.

23. Windhager, E. E., and G. Giebisch. Micropuncture study of renal tubular transfer of sodium chloride in the rat. Amer. J. Physiol. 1961, 200, 581.

24. Westfall, B. B., J. Findley, and A. N. Richards. Quantitative studies of the composition of glomerular urine XII. The concentration of chloride in glomerular urine of frogs and Necturi. J. biol. Chem. 1934, 107, 661.

25. Chen, P. S., Jr., T. Y. Toribara, and H. Warner. Microdetermination of phosphorus. Analyt. Chem. 1956, 28, 1756.

26. Toribara, T. Y., A. R. Terepka, and P. A. Dewey. The ultrafilterable calcium of human serum. I. Ultrafiltration methods and normal values. J. clin. Invest. 1957, 36, 738.

27. Hawk, P. B., B. L. Oser, and W. H. Summerson. Practical Physiological Chemistry, 13th ed. New York, Blakiston, 1947, pp. 605-607.

28. Kenny, A. D. Survival and serum calcium levels of rats after parathyroidectomy. Endocrinology 1962, 70, 715.

29. Lassiter, W. E., C. W. Gottschalk, and M. Mylle. Micropuncture study of net transtubular movement of water and urea in nondiuretic mammalian kidney. Amer. J. Physiol. 1961, 200, 1139.

30. Giebisch, G., R. M. Klose, and E. E. Windhager. Micropuncture study of hypertonic sodium chloride loading in the rat. Amer. J. Physiol., in press.

31. Walser, M. Protein-binding of inorganic phosphate in plasma of normal subjects and patients with renal disease. J. clin. Invest. 1960, 39, 501.

32. Van Slyke, D. D., H. Wu, and F. C. McLean. Studies of gas and electrolyte equilibria in the blood. V. Factors controlling the electrolyte and water distribution in the blood. J. biol. Chem. 1923, 56, 65. 
33. Benjamin, H. R., and A. F. Hess. The forms of the calcium and inorganic phosphorus in human and animal sera. I. Normal, rachitic, hypercalcemic, and other conditions. J. biol. Chem. 1933, 100, 27.

34. Carone, F. Personal communication.

35. Marsh, D. J., K. J. Ullrich, and G. Rumrich. Micropuncture analysis of the behavior of potassium ions in rat renal cortical tubules. Pflügers Arch. ges. Physiol. 1963, 277, 107.

36. Bloomer, H. A., F. C. Rector, Jr., and D. W. Seldin. The mechanism of potassium reabsorption in the proximal tubule of the rat. J. clin. Invest. 1963, 42, 277.
37. Lassiter, W. E., C. W. Gottschalk, and M. Mylle. Micropuncture study of renal tubular reabsorption of calcium in normal rodents. Amer. J. Physiol. 1963, 204, 771.

38. Solomon, S. Transtubular potential differences of rat kidney. J. cell. comp. Physiol. 1957, 49, 351.

39. Gerlach, E., W. Bader, and W. Schwoerer. Uber den Stoffwechsel saureloslicher Phosphor-Verbindungen in der Ratteuniere. Pflügers Arch. ges. Physiol. 1961, 272, 407.

40. Whittam, R. The permeability of kidney cortex to chloride. J. Physiol. (Lond.) 1956, 131, 542.

41. Aebi, H. Elektrolyt-Akkumulierung und Osmoregulation in Gewebsschnitten. Helv. physiol. Pharmacol. Acta 1953, 11, 96. 